\title{
Symptom management for patients awaiting joint replacement surgery
}

Chris Wall, Theresa Johnson, Richard de Steiger

\section{Background \\ Joint replacement surgery is a highly effective treatment option for patients with severe osteoarthritis (OA) of the hip and knee when other treatments have failed. Unfortunately, as a result of the COVID-19 pandemic, a temporary suspension of non-urgent elective surgery was implemented. Thousands of patients currently awaiting hip and knee replacements have been affected. Many of these patients will present to their general practitioners for symptom management during this interim period.}

\section{Objective}

The purpose of this article is to summarise current recommendations for the non-operative management of patients with symptomatic OA.

\section{Discussion}

Non-operative treatment modalities for OA include education, lifestyle modification and exercise, mass reduction, physiotherapy, orthoses, psychology, pharmaceuticals and injections. Multimodal therapy is required for patients with severe symptoms. A number of useful online resources are presented, as access to public allied health services may be limited because of the COVID-19 pandemic.
OSTEOARTHRITIS (OA) of the hip and knee are common orthopaedic conditions, frequently causing pain and disability. The incidence of OA is steadily increasing. ${ }^{1}$ Joint replacement surgery has revolutionised the management of OA but should be reserved for patients who have not responded to non-operative therapies. Joint replacement is very cost-effective and provides long-term improvements in pain, mobility and quality of life for most patients. ${ }^{2,3}$

In Australia, more than 105,000 primary and revision hip and knee replacements were performed in 2018 , and approximately $35 \%$ of these operations were performed in the public sector. ${ }^{4,5}$ The projected burden of primary total hip and knee replacement in Australia is expected to increase by $208 \%$ and $276 \%$, respectively, by the year $2030 .^{6}$

Unfortunately, as a result of the COVID-19 pandemic, a nationwide, temporary suspension of non-urgent elective surgery was implemented. Thousands of patients waiting for joint replacement surgery have been affected. Although the restrictions are being eased, patients may still experience delays as health services manage their waiting lists. Many affected patients will present to their general practitioners for symptom management in the interim period.

The purpose of this article is to discuss non-operative management options for patients with severe OA. Although prompted by recent elective surgery suspensions, the principles presented are equally applicable to patients who are unfit for surgery, or patients using the public system who may wait 365 days for their joint replacement, according to National Categorisation Guidelines. ${ }^{7}$
The management approach is essentially the same as for patients with milder symptoms; however, it may be necessary to use several treatment modalities. ${ }^{8}$ Different treatment modalities are discussed in the remainder of this article.

\section{Education}

OA is a chronic condition, and patient education plays an important part in management. ${ }^{9,10}$ Patients need to understand the natural history of the condition and treatment options available. Misconceptions about OA are common, particularly about the positive role of regular low-impact cardiovascular exercise and muscle-strengthening exercises, and these misconceptions should be corrected. Misconceptions about chronic pain are also common, and education plays an important part in management. Box 1 lists a number of online patient education resources that may be beneficial.

Many patients will be anxious and upset about the suspension of elective surgery. However, these decisions were not made lightly, and it is important to explain that they were made in the best interest of both the individual patient and our nation's healthcare. As restrictions ease, health services are focusing on reinstating patients on elective operating lists as expediently as possible.

\section{Lifestyle modification and exercise In general, avoidance of activities that significantly aggravate the patients' symptoms is advisable. For lower limb OA, avoiding high-impact activities may be}


beneficial. However, there is a common misconception that weight-bearing activity and joint movement may cause further cartilage damage. In fact, there is evidence that regular low-impact cardiovascular exercise and regular peri-articular strengthening and range-of-motion exercises are beneficial for reducing the symptoms of OA. ${ }^{11,12}$ GLA:D International (Good Life with osteoArthritis: Denmark) has produced a series of educational videos about home-based joint exercises; these videos are freely available on YouTube (Box 1).

\section{Mass reduction}

The link between obesity and knee OA is well established. ${ }^{13}$ Even modest weight loss can reduce patients' symptoms. ${ }^{14}$ For patients who are obese, weight loss may also reduce the risk of subsequent anaesthesia and major surgery. Engagement with a dietitian, exercise physiologist and/or physiotherapist to provide advice on healthy dieting and regular cardiovascular exercise may be beneficial.

\section{Physiotherapy}

Musculoskeletal physiotherapists play an important part in the non-operative management of OA. Periarticular muscle strengthening, gait retraining and core strengthening are beneficial to both reduce symptoms pre-operatively and improve recovery postoperatively. ${ }^{11,12}$ Physiotherapists can also provide mobility assessments and advise on the use of gait aids to minimise pain while weight bearing, improve ambulation and reduce the risk of falls.

Access to allied health services during the COVID-19 pandemic may be limited, particularly in the public sector. GLA:D International's instructional videos may be beneficial at this time.

\section{Orthoses}

Gait aids - including walking sticks, crutches and walking frames - can allow patients with severe OA to maintain a degree of mobility and independence. ${ }^{15}$ When used correctly, these devices transmit weight from the affected lower limb to the upper limbs. In general, a walking stick should be used in the contralateral hand for hip and knee OA. A physiotherapist can prescribe an appropriate gait aid and train the patient in its correct use.

For patients with severe OA for whom any weight bearing is intolerable or unsafe, a wheelchair or motorised scooter may be used to maintain mobility. An occupational therapist can provide advice on these devices.

There is no evidence to support the use of knee braces or orthotics for the treatment of knee OA. ${ }^{16}$

\section{Psychology}

Patients with chronic pain due to OA commonly experience anxiety and depression. ${ }^{17}$ The added stress of elective surgery suspensions, along with other stresses associated with the COVID-19 pandemic, may exacerbate these conditions. Proactively addressing these issues is advocated.

\section{Pharmaceuticals}

A stepwise approach to analgesia is recommended. ${ }^{10}$ Non-opioid agents such as paracetamol and cyclooxygenase-2 (COX-2) selective nonsteroidal anti-inflammatory drugs (NSAIDs) should be used for appropriate patients. Opioids should be avoided where possible. However, these may be considered for patients in severe pain for whom surgery has been postponed.
Topical NSAIDs and capsaicin may be beneficial. ${ }^{18,19}$

Regarding complementary medicines, glucosamine and chondroitin sulphate are no more effective than placebo. ${ }^{20,21}$ Fish oils and turmeric have mild anti-inflammatory effects, but there is insufficient evidence to support their use. ${ }^{9}$

\section{Injections}

Intra-articular injections of cortisone may provide temporary symptomatic relief for patients with OA. ${ }^{9}$ These are commonly used in the knee and may be administered with or without imaging guidance.

Intra-articular cortisone injections for the hip are less common and require imaging guidance. Pain relief after cortisone injections is variable, and any relief is generally temporary. Intra-articular injections of hyaluronic acid should not be recommended. ${ }^{9}$

Judicious use of cortisone injections may be considered for patients with significant symptoms when joint replacement surgery is temporarily unavailable. However, there is an increased risk of periprosthetic infection in joint replacements performed within three months of an intra-articular injection..$^{22,23}$ It is therefore not advisable to consider injections when surgery is likely to occur within three months. Communication with the local orthopaedic service is recommended.

At present, there is insufficient evidence to support the use of platelet-rich plasma or stem cell therapy for patients with OA, and these options are very expensive.

\section{Box 1. Online patient education resources for osteoarthritis management}

Understanding osteoarthritis

- Osteoarthritis Australia - My Joint Pain, www.myjointpain.org.au

- Osteoarthritis Research Society International (OARSI) - Patients, www.oarsi.org/patients

Chronic pain management

- NSW Government Agency for Clinical Innovation - Brainman Pain Management Resources, www.aci.health.nsw.gov.au/ie/projects/brainman

- This Way Up - Chronic Pain - Reboot, https://thiswayup.org.au/how-we-can-help/courses/ chronic-pain

Home-based joint exercises

- GLA:D International YouTube channel, www.youtube.com/channel/ UCP8RbOupT5GgQarss0Ybt8g/videos 


\section{Conclusion}

The healthcare impact of the COVID-19 pandemic in other countries has been devastating. The Australian Government is actively implementing strategies to mitigate the impact of the pandemic in our country. One unfortunate consequence has been the temporary suspension of non-urgent elective surgery. Thousands of patients awaiting joint replacement surgery have been affected. Patients with severe OA will need multimodal non-operative management during this challenging time.

\section{Authors}

Chris Wall MBBS, BMedSc, FRACS, FAOrthA, Deputy Director, Department of Orthopaedics, Toowoomba Hospital, Qld; Senior Lecturer, School of Medicine, Rural Clinical School, University of Queensland; Qld. Chris.Wall@health.qld.gov.au Theresa Johnson MBBS, BSc, FACRRM, General Practice Liaison Officer, Darling Downs Hospital and Health Service, Qld

Richard de Steiger MBBS, PhD, Dip Biomech, FRACS, FAOrthA, Epworth Victor Smorgon Chair of Surgery, The University of Melbourne, Vic; Deputy Director, Australian Orthopaedic Association National Joint Replacement Registry, SA

Competing interests: None.

Funding: None.

Provenance and peer review: Not commissioned, externally peer reviewed.

\section{References}

1. Cross M, Smith E, Hoy D, et al. The global burden of hip and knee osteoarthritis: Estimates from the global burden of disease 2010 study. Ann Rheum Dis 2014;73(7):1323-30. doi: 10.1136/ annrheumdis-2013-204763.

2. Learmonth ID, Young C, Rorabeck C. The operation of the century: Total hip replacement. Lancet 2007;370(9597):1508-19. doi: 10.1016/ S0140-6736(07)60457-7.
3. Daigle ME, Weinstein AM, Katz JN, Losina E The cost-effectiveness of total joint arthroplasty: A systematic review of published literature. Best Pract Res Clin Rheumatol 2012;26(5):649-58. doi: 10.1016/j.berh.2012.07.013.

4. Australian Orthopaedic Association National Joint Replacement Registry (AOANJRR). Hip, knee \& shoulder arthroplasty: 2019 Annual Report. Adelaide: AOA, 2019.

5. Australian Orthopaedic Association National Joint Replacement Registry (AOANJRR). Analysis of state and territory health data. All arthroplasty 1993/1994-2017/2018. Adelaide: AOA, 2019.

6. Ackerman IN, Bohensky MA, Zomer E, et al. The projected burden of primary total knee and hip replacement for osteoarthritis in Australia to the year 2030. BMC Musculoskelet Disord 2019;20(1):90. doi: 10.1186/s12891-019-2411-9.

7. Australian Health Ministers' Advisory Council. National elective surgery urgency categorisation. Adelaide: AHMAC, 2015.

8. Victorian Musculoskeletal Clinical Leadership Group. Victorian model of care for osteoarthritis of the hip and knee. Melbourne, Vic: MOVE muscle, bone \& joint health, 2018.

9. The Royal Australian College of General Practitioners. Guideline for the management of knee and hip osteoarthritis. 2nd edn. East Melbourne, Vic: RACGP, 2018.

10. Australian Commission on Safety and Quality in Health Care. Osteoarthritis of the knee clinical care standard. Sydney: ACSQHC, 2017.

11. Fransen M, McConnell S, Harmer AR, Van der Esch M, Simic M, Bennell KL. Exercise for osteoarthritis of the knee: A Cochrane systematic review. Br J Sports Med 2015;49(24):1554-57. doi: 10.1136/bjsports-2015-095424.

12. Quicke JG, Foster NE, Thomas MJ, Holden MA. Is long-term physical activity safe for older adults with knee pain?: A systematic review. Osteoarthritis Cartilage 2015;23(9):1445-56 doi: 10.1016/j.joca.2015.05.002.

13. Wang Y, Wluka AE, Simpson JA, et al. Body weight at early and middle adulthood, weight gain and persistent overweight from early adulthood are predictors of the risk of total knee and hip replacement for osteoarthritis. Rheumatology (Oxford) 2013:52(6):1033-41. doi: 10.1093/ rheumatology/kes419.

14. Christensen R, Bartels EM, Astrup A, Bliddal $H$. Effect of weight reduction in obese patients diagnosed with knee osteoarthritis: A systematic review and meta-analysis. Ann Rheum Dis
2007;66(4):433-39. doi: 10.1136/ard.2006.065904.

15. Jones A, Silva PG, Silva AC, et al. Impact of cane use on pain, function, general health and energy expenditure during gait in patients with knee osteoarthritis: A randomised controlled trial. Ann Rheum Dis 2012;71(2):172-79. doi: 10.1136/ ard.2010.140178.

16. Duivenvoorden T, Brouwer RW, van Raaij TM, Verhagen AP, Verhaar JAN, Bierma-Zeinstra SM Braces and orthoses for treating osteoarthritis of the knee. Cochrane Database Syst Rev 2015;(3):CD004020. doi: 10.1002/14651858. CD004020.pub3.

17. Stubbs B, Aluko Y, Myint PK, Smith TO. Prevalence of depressive symptoms and anxiety in osteoarthritis: A systematic review and meta-analysis. Age Ageing 2016;45(2):228-35. doi: 10.1093/ageing/afw001.

18. Persson MSM, Stocks J, Walsh DA, Doherty M, Zhang W. The relative efficacy of topical nonsteroidal anti-inflammatory drugs and capsaicin in osteoarthritis: A network meta-analysis of randomised controlled trials. Osteoarthritis Cartilage 2018;26(12):1575-82. doi: 10.1016/j. joca.2018.08.008.

19. Zeng C, Wei J, Persson MSM, et al. Relative efficacy and safety of topical non-steroidal anti-inflammatory drugs for osteoarthritis: A systematic review and network meta-analysis of randomised controlled trials and observational studies. Br J Sports Med 2018;52(10):642-50. doi: 10.1136/bjsports-2017-098043.

20. Clegg DO, Reda DJ, Harris CL, et al. Glucosamine, chondroitin sulfate, and the two in combination for painful knee osteoarthritis. N Engl J Med 2006;354(8):795-808. doi: 10.1056/ NEJMoa052771.

21. Sawitzke AD, Shi H, Finco MF, et al. Clinical efficacy and safety of glucosamine, chondroitin sulphate, their combination, celecoxib or placebo taken to treat osteoarthritis of the knee: 2-year results from GAIT. Ann Rheum Dis 2010;69(8):1459-64. doi: 10.1136/ard.2009.120469.

22. Richardson SS, Schairer WW, Sculco TP, Sculco PK. Comparison of infection risk with corticosteroid or hyaluronic acid injection prior to total knee arthroplasty. J Bone Joint Surg Am 2019;101(2):112-18. doi: 10.2106/JBJS.18.00454.

23. Werner BC, Cancienne JM, Browne JA. The timing of total hip arthroplasty after intraarticular hip injection affects postoperative infection risk. J Arthroplasty 2016:31(4):820-23. doi: 10.1016/j. arth.2015.08.032. 